\title{
Metabolism of Drugs of Abuse: Its Contribution to the Toxicity and the Inter-Individual Differences in Drug Sensitivity
}

\author{
Hideyuki Yamada, ${ }^{*}, a$ Yuji Ishii, ${ }^{a}$ and Kazuta Oguri ${ }^{b}$ \\ ${ }^{a}$ Graduate School of Pharmaceutical Sciences, Kyushu University, 3-1-1 Maidashi, Higashi-ku, Fukuoka 812-8582, Japan and ${ }^{b}$ School \\ of Pharmaceutical Sciences, Kyusyu University of Health and Welfare, 1714-1 Yoshino-machi, Nobeoka 882-8508, Japan
}

(Received October 15, 2004)

\begin{abstract}
Abuse of drugs remains a serious and world-wide problem. As exemplified by opioids, there are large interindividual differences in the effects and toxicity of drugs. However, the mechanism underlying such inter-individual differences remains largely unknown. Since, in many cases, drug metabolism affects the effects of drugs, the different metabolic capacity of individuals may explain these inter-individual differences. In this review, we shall focus on drugs of abuse and survey briefly their metabolism and the enzymes involved. In addition, we shall discuss the putative origin of the inter-individual differences in sensitivity to drugs of abuse.
\end{abstract}

Key words — abused drug, metabolism, inter-individual difference, methamphetamine, morphine

\section{INTRODUCTION}

Drug abuse remains a world-wide problem its impact on society is increasing. In addition to the abuse of classical drugs, such as heroin, cocain and methamphetamine, a number of new drugs have appeared. Unfortunately, it is generally expected that acute intoxication and drug-related crime will continue to increase. To help solve this problem, the general public needs to be taught about the adverse effects of drug abuse as far as mental and physical health, and social cohesion are concerned. Advances in the development of specific and sensitive techniques for the analysis of abused drugs in body will help address this problem. In addition, forensic toxicologists need more information about the metabolism of abused drugs and the underlying mechanisms. This is because drug concentrations in the body largely depend on metabolism. Furthermore, it is well-known that inter-individual differences in metabolic capacity can partially explain differences

*To whom correspondence should be addressed: Graduate School of Pharmaceutical Sciences, Kyushu University, 3-1-1 Maidashi, Higashi-ku, Fukuoka 812-8582, Japan. Tel.: +81-92642-6585; Fax: +81-92-642-6588; E-mail: yamada@xenoba. phar.kyushu-u.ac.jp in drug sensitivity, although there are many cases which cannot be understood simply by the single nucleotide polymorphisms (SNPs) of genes coding drug metabolizing enzymes. In this review, we shall focus on the metabolism of drugs of abuse, and discuss the significance of this in terms of their toxicity.

\section{AMPHETAMINES INCLUDING MDMA}

The metabolic fate of amphetamine (AP) and methamphetamine (MP) in man have been described in detail by Caldwell, Williams and their colleagues. ${ }^{1-4)}$ Although unchanged AP and MP are easily detectable in urine of abusers, a large fraction of these drugs is metabolized in the body following absorption. The major metabolites of AP in man are $p$-hydroxy-AP and benzoic acid including its glycine conjugate (Fig. 1A). ${ }^{1)}$ While a portion of the MP ingested is $N$-demethylated to AP, the other pathways of MP metabolism are similar to those of AP., ${ }^{2,4}$ For example, MP is also converted to $p$-hydroxylated metabolites and benzoic acid (Fig. 1A). The difference in the metabolism is that the formation of deaminated product (benzoic acid) from AP is greater than that from MP. The $N$-demethylation of MP pro- 

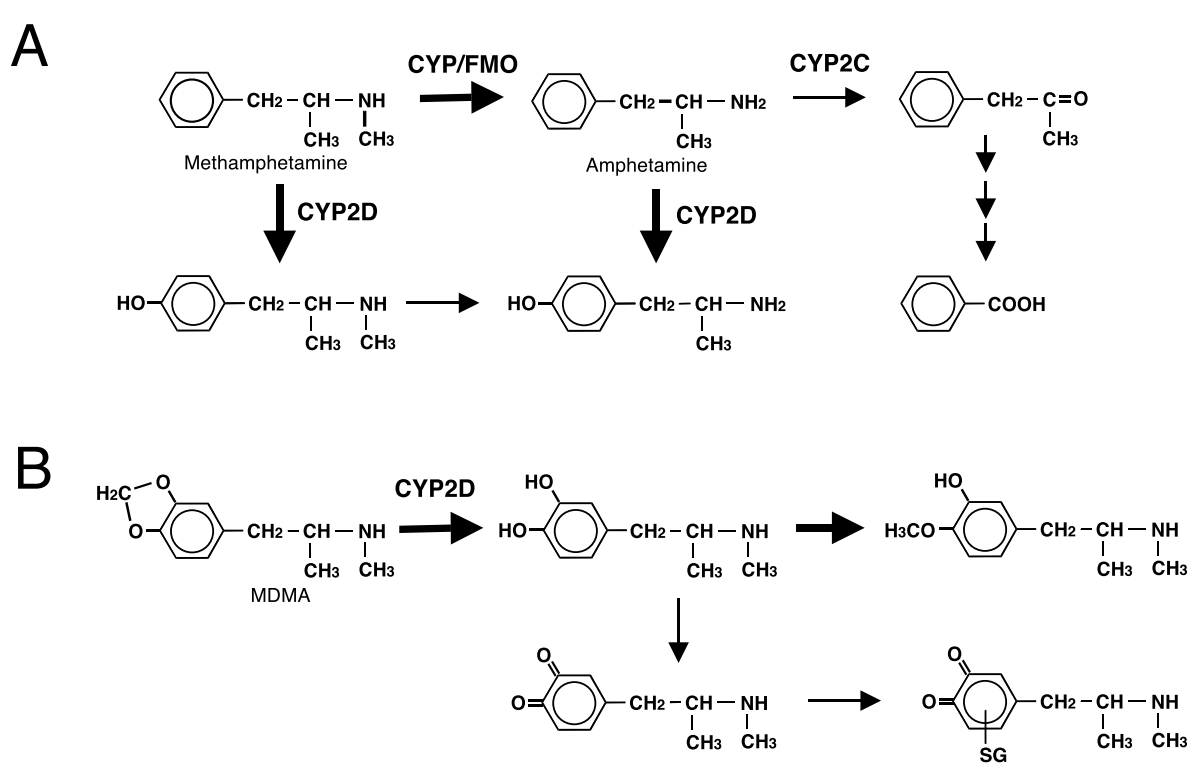

Fig. 1. Metabolic Pathways of MP (A) and MDMA (B)

Major metabolic pathway is indicated by bold arrow. As this figure does not show all minor pathways, see references 1-4 (MP) and 15 (MDMA) for the details. CYP and FMO shown above arrow mean cytochrome P450 and flavin-containing monooxygenase, respectively, which are mainly involved in the metabolism. In the figure B, -SG shows the conjugated metabolite with glutathione.

duces an active metabolite, AP. However, because AP and MP have almost equivalent stimulant potency, it is unlikely that the degree of $N$ demethylation markedly affects the action of MP. On the other hand, aromatic hydroxylation and deamination of AP/MP are thought to be detoxication pathways, although early studies have raised the possibility that $p$-hydroxylated metabolites may contribute to chronic psychological effects by affecting catecholamine levels. ${ }^{5,6)}$ The cytochrome P450 ( $\mathrm{P} 450)$ participating in the deamination of AP/MP has been suggested to be an isoform of the CYP2C subfamily (Fig. 1A). ${ }^{7,8}$ This suggests the possibility that polymorphism(s) for the CYP2C enzyme contributes to the inter-individual differences in AP/MP action. However, this is not certain and needs to be proved.

Aromatic hydroxylation of AP/MP has been shown to be catalyzed by CYP2D enzymes. ${ }^{9-11)}$ The importance of this detoxication pathway on MP action can be understood by the observation that the difference in the stimulating effect of MP stereoisomers $(d>l)$ reversely correlates with the difference in the $p$-hydroxylation by CYP2D enzyme $(l>d) .{ }^{10)}$ It is well-known that this isoform of P450 exhibits inter-individual differences in its expression and function. ${ }^{12)}$ About 0.7 and $7 \%$ of Japanese and Caucasians are poor metabolizers, respectively, due to the lack of or reduced catalytic function of CYP2D6.
Although the serum level of MP in the poor metabolizers (PM) does not markedly differ from that in the extensive metabolizers (EM), PM are reported to be more sensitive to the pharmacological action of MP. ${ }^{13)}$ In addition, CYP2D polymorphism affects developmental neurotoxicity in rats produced by maternal exposure to MP. ${ }^{14)}$ This suggests that the higher sensitivity exhibited by PM metabolizers toward MP action is due to the higher concentration of the drug in brain. ${ }^{13)}$

The polymorphism for CYP2D is also suggested to be involved in the psychological toxicity produced by methylenedioxy-MP (MDMA). The demethylenation of MDMA is mainly catalyzed by CYP2D6 (Fig. 1B). ${ }^{10,11,15)}$ whereas other forms of P450, such as CYP1A2, CYP2B6 and CYP3A4, are also capable of mediating this metabolic conversion. ${ }^{16)}$ The demethylenation of MDMA results in a catechol derivative of MP which may produce neurotoxicity following conversion to a reactive quinone (Fig. 1B). ${ }^{17)}$ Thus, CYP2D polymorphism may affect the occurrence of MDMA neurotoxocity. However, it should be noted that a report disagreeing with this hypothesis has been published. In Dark Agouti (DA) rats, while the male is an extensive metabolizer as far as CYP2D polymorphism is concerned, the female is a poor metabolizer. On comparing the MDMA-induced elevation of body temperature which also occurs in humans ingesting MDMA, the 


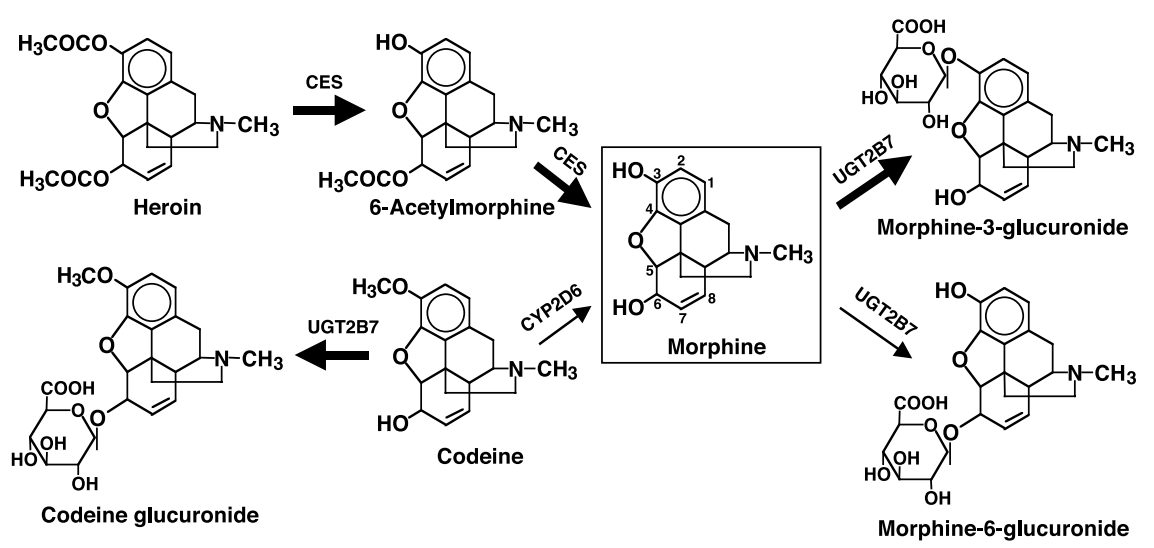

Fig. 2. Metabolic Pathways of Morphine, Heroin and Codeine Bold arrows indicate major metabolic pathways.

symptom has also been found in female DA rats. ${ }^{18)}$ Therefore, the possibility that CYP2D polymorphism significantly affects MDMA action needs further study to confirm its validity.

\section{OPIOIDS}

It has long been known that there are great inter-individual differences in the pharmacological effects of morphine and heroin. Glucuronidation of the 3- and 6-hydroxy groups is the main metabolic pathway of morphine (Fig. 2). ${ }^{19,20)}$ The same is true for heroin, although this drug requires hydrolysis of the 3- and 6-acetoxy groups before glucuronidation (Fig. 2). It is well-known that the main metabolite, morphine-3-glucuronide (M-3-G), is a detoxified metabolite, and the 6-glucuronide (M-6-G) has far greater analgesic activity than the parent compound. ${ }^{21-24)}$ As the ratio of free morphine to total morphine, including its glucuronides, is a useful index for assessing the magnitude of acute intoxication by morphine and heroin ${ }^{25}$ ) it is likely that the catalytic activity for 3-glucunonide formation is at least one of the determinants of sensitivity to these drugs. The major isoform of human UDPglucuronosyltransferase (UGT) responsible for morphine 3- and 6-conjugation is assumed to be UGT2B7. ${ }^{26)}$ Many types of SNP have been reported for the UGT2B7 gene. ${ }^{27-30)}$ Although base substitutions for these SNPs between morphine-responders and non-responders have been reported ${ }^{29)}$ it remains unknown whether these SNPs have an effect on UGT2B7 function. At least two SNPs, UGT2B7*1 and $* 2$, discovered in the coding region of the
UGT2B7 gene have been shown not to affect enzymatic function. ${ }^{31)}$ In connection with this, it has been suggested that factors other than UGT2B7 polymorphism may affect the variability in the serum ratio of morphine glucuronide to morphine. ${ }^{28)}$ On the other hand, Duguay et al. have demonstrated that SNPs at the promoter region of the UGT2B7 gene affect transcription. ${ }^{32}$ Thus, although the SNPs for the UGT2B7 gene may explain at least partially the inter-individual differences in morphine sensitivity, much more effort will be needed to establish this beyond doubt. Alternatively, it is conceivable that the SNPs for the opioid receptor gene can explain the different sensitivity of individuals to opioids. The human $\mu$-opioid receptor, encoded in the OPRMI gene, ${ }^{33,34)}$ is the major site for the analgesic action of opioids. The mutant allele of the 118A > G SNP in the OPRM1 gene, which codes an Asn40Asp $\mu$ opioid receptor, has been associated with reduced opioid activity in carriers of the $118 \mathrm{G}$ allele. ${ }^{35)}$ The polymorphism A118G of the human OPRM1 gene may be responsible for the different sensitivity towards M-6-G but not morphine. ${ }^{35)}$ In addition, evidence from clinical studies points to the functional importance of several OPRMI SNPs as far as opioid addiction is concerned ${ }^{36)}$ However, the SNPs of opioid receptors reported thus far do not seem to fully explain the inter-individual differences in sensitivity towards morphine. ${ }^{37)}$ Interestingly, oligomerization of opioid receptors has been reported. ${ }^{38)}$ Heterodimeric associations between $\mu-\delta$ opioid receptors have been shown, ${ }^{39)}$ and this report also suggested that the occupancy of $\delta$ receptors with antagonists enhances its binding to $\mu$ opioid receptors, resulting in increased signaling activity. Further- 
more, $\delta$ receptor antagonists enhance morphine-mediated intrathecal analgesia. Thus, receptor-receptor interaction between opioid receptors and SNPs of opioid receptor genes need to be investigated to increase our understanding of alterations in opioid effects.

Current studies in our laboratory have suggested a distinct mechanism which may explain inter-individual differences in the ability to metabolize morphine in humans. In these studies, we have examined a hypothesis that UGT function is changed by protein-protein interaction with $\mathrm{P} 450$. This hypothesis is based on an observation which showed effective trapping of UGTs by a P450-immobilized column. ${ }^{40)}$ In support of this, our recent data suggest that $\mathrm{P} 450$ functions as a substrate supplier to UGT; ${ }^{41)}$ and P450 associates with UGT to alter its function. ${ }^{42)}$ As far as the latter possibility is concerned, we observed a CYP3A4-dependent alteration of UGT2B7 function using morphine glucuronidation as the index. This suggests that the polymorphic expression of CYP3A4 is one of the determinants regulating the bioavailability of morphine. However, this should be further examined by clinical studies in volunteers.

The phamacological effect of heroin is thought to depend on its hydrolyzed metabolites, 6acetylmorphine and morphine. In agreement with this, esterase inhibition increases the effect of heroin but not morphine in mice. ${ }^{43)}$ It has been suggested that the pharmacological effect of heroin and morphine is different because the specific receptor for 6 -acetylmorphine differs from that for morphine. ${ }^{44)}$ If this is true, an inter-individual difference in heroin hydrolase(s) would affect the effect and development of dependency produced by this dangerous drug. Regarding this, human carboxylesterases (CES) 1 and 2 can hydrolyze both the 3- and 6-acetoxy groups of heroin. ${ }^{45,46)}$ CES2 has been suggested to play a more important role than CES1 in heroin metabolism. However, to the best of our knowledge, the relationship between the polymorphism of human CESs and its impact on the metabolism and pharamacological effect of heroin has not yet been reported.

It is also of interest that CYP2D polymorphism is involved in the inter-individual differences in codeine pharmacology. This drug has long been used as a safe analgesic and cough medicine. UGT2B7 catalyzes codeine glucuronidation as well as morphine metabolism (Fig. 2), but codeine is a much poorer substrate of this enzyme. ${ }^{26)}$ This seems to be one of the reasons why codeine resists the first-pass effect. The analgesic activity of codeine is thought to largely depend on its $O$-demethylated metabolite, morphine, which is produced by catalysis involving the CYP2D subfamily (Fig. 2) ${ }^{47)}$ Codeine cannot produce its analgesic activity in about $10 \%$ of Caucasians. ${ }^{48)}$ As this is roughly consistent with the population of CYP2D poor metabolizers, it is likely that the CYP2D enzyme plays a major role in codeine analgesic activity and dependency.

\section{COCAINE AND TETRAHYDRO- CANNABINOL}

The main metabolic pathway of cocaine is hydrolysis to benzoylecgonine and ecgonine methyl ester. These reactions are catalyzed by serum butyrylcholine esterase and hepatic CES2. ${ }^{46,49)}$ The contribution of these esterases to cocaine disappearance remains to be clarified. However, as the addition of butyrylcholine esterase to blood containing cocaine results in a marked reduction in its concentration, this enzyme must play an important role. ${ }^{50}$ While the inter-individual differences in cocaine hydrolysis remain largely unknown, it has been reported that there are individuals exhibiting an extremely low excretion of ecgonine methyl ester following cocaine ingestion. ${ }^{51)}$ Thus, it is likely that differences in sensitivity to cocaine are linked to polymorphism of cocaine esterase(s).

Tetrahydrocannabinol (THC), an active ingredient in marihuana, is mainly metabolized via oxidation of the methyl group (C11) at the $\mathrm{C} 9$ position to give the carboxylic acid derivative. As the human liver microsomal activity of THC 11-hydroxylation is markedly inhibited by anti-CYP2C9 antibody, ${ }^{52)}$ this subfamily is likely to play a major role. Watanabe et al. have reported that a purified preparation of mouse P450 (Cyp2c29) catalyzes the conversion of THC to the 9-carboxylic acid. ${ }^{53)}$ This means that CYP2C enzyme(s) catalyzes the oxygenation of the aldehyde intermediate as well as the formation of $11-\mathrm{OH}$ and its aldehyde, although non-P450 oxidases also contribute to the formation of the carboxylate metabolite. To date, few studies have been undertaken to investigate the relationship between the metabolic capacity of individuals and THC action. 


\section{FUTURE PERSPECTIVES}

The mechanism of the different sensitivity of individuals to drugs of abuse remains largely unknown, even although these drugs have been abused for a long time. Clarification of these issues would help in the prevention of abuse and the treatment of intoxication by these drugs. As discussed, differences in the sensitivity to drugs may be due not only to the SNPs in the genes, but also to an alteration in the function of drug metabolizing enzymes by proteinprotein interaction. To identify the factors involved in the inter-individual differences in drug sensitivity, more studies are needed from both basic and clinical standpoints. In addition, studies of the metabolism of novel synthetic drugs and their possible toxic effects will also be required.

\section{REFERENCES}

1) Dring, L. G., Smith, R. L. and Williams, R. T. (1970) The metabolic fate of amphetamine in man and other species. Biochem. J., 116, 425-435.

2) Caldwell, J., Dring, L. G. and Williams, R. T. (1972) Metabolism of $\left({ }^{14} \mathrm{C}\right)$ methamphetamine in man, the guinea pig and the rat. Biochem. J., 129, 11-22.

3) Caldwell, J., Dring, L. G. and Williams, R. T. (1972) Norephedrines as metabolites of $\left({ }^{14} \mathrm{C}\right)$ amphetamine in urine in man. Biochem. J., 129, 23-24.

4) Caldwell, J., Dring, L. G. and Williams, R. T. (1972) Biliary excretion of amphetamine and methamphetamine in the rat. Biochem. J., 129, 25-29.

5) Cho, A. K., Schaffer, J. C. and Fischer, J. F. (1975) Accumulation of 4-hydroxyamphetamine by rat striatal homogenates. Biochem. Pharmacol., 24, 15401542.

6) Cho, A. K., Fischer, J. F. and Schaeffer, J. C. (1977) The accumulation of p-hydroxyamphetamine by brain homogenates and its role in the release of catecholamines. Biochem. Pharmacol., 26, 1367-1372.

7) Yamada, H., Honda, S., Oguri, K. and Yoshimura, H. (1989) A rabbit liver constitutive form of cytochrome $\mathrm{P} 450$ responsible for amphetamine deamination. Arch. Biochem. Biophys., 273, 26-33.

8) Shiiyama, S., Soejima-Ohkuma, T., Honda, S., Kumagai, Y., Cho, A. K., Yamada, H., Oguri, K. and Yoshimura, H. (1997) Major role of the CYP2C isoenzymes in deamination of amphetamine and benzphetamine: evidence for the quinidine-specific inhibition of the reactions catalysed by rabbit enzyme. Xenobiotica, 27, 379-387.

9) Smith, R. L. (1986) Human genetic variations in oxidative drug metabolism: Introduction. Xenobiotica, 16, 361-365.

10) Lin, L. Y., Kumagai, Y., Hiratsuka, A., Narimatsu, S., Suzuki, T., Funae, Y., Distefano, E. W. and Cho, A. K. (1995) Cytochrome P4502D isozymes catalyze the 4-hydroxylation of methamphetamine enantiomers. Drug Metab. Dispos., 23, 610-614.

11) Lin, L. Y., Di Stefano, E. W., Schmitz, D. A., Hsu, L., Ellis, S. W., Lennard, M. S., Tucker, G. T. and Cho, A. K. (1997) Oxidation of methamphetamine and methylenedioxymethamphetamine by CYP2D6. Drug Metab. Dispos., 25, 1059-1064.

12) Nagata, K. and Yamazoe, Y. (2002) Genetic polymorphism of human cytochrome P450 involved in drug metabolism. Drug Metab. Pharmacokinet., 17, 167-189.

13) Sellers, E. M. and Tyndale, R. F. (2000) Mimicking gene defects to treat drug dependence. Ann. N.Y. Acad. Sci., 909, 233-246.

14) Vorhees, C. V., Morford, L. L., Inman, S. L., Reed, T. M., Schilling, M. A., Cappon, G. D., Moran, M. S. and Nebert, D. W. (1999) Genetic differences in spatial learning between Dark Agouti and SpragueDawley strains: possible correlation with the CYP2D2 polymorphism in rats treated neonatally with methamphetamine. Pharmacogenetics, 9, 171181.

15) de la Torre, R., Farre, M., Roset, P. N., Pizarro, N., Abanades, S., Segura, M., Segura, J. and Cami, J. (2004) Human pharmacology of MDMA: pharmacokinetics, metabolism, and disposition. Ther. Drug Monit., 26, 137-144.

16) Kreth, K., Kovar, K., Schwab, M. and Zanger, U. M. (2000) Identification of the human cytochromes $\mathrm{P} 450$ involved in the oxidative metabolism of "Ecstasy"-related designer drugs. Biochem. Pharmacol., 59, 1563-1571.

17) Hiramatsu, M., Kumagai, Y., Unger, S. E. and Cho, A. K. (1990) Metabolism of methylenedioxymethamphetamine: formation of dihydroxymethamphetamine and a quinone identified as its glutathione adduct. J. Pharmacol. Exp. Ther., 254, 521527.

18) Colado, W. J. L. and Green, A. R. (1995) The hyperthermic and neurotoxic effects of 'Ecstasy' (MDMA) and 3,4 methylenedioxyamphetamine (MDA) in the Dark Agouti (DA) rat, a model of the CYP2D6 poor metabolizer phenotype. $\mathrm{Br} . J$. Pharmacol., 115, 1281-1289.

19) Fujimoto, J. M. and Way, E. L. (1957) Isolation and crystallization of "blood" morphine from urine of human addicts. J. Pharmacol. Exp. Ther., 121, 340346.

20) Yoshimura, H., Oguri, K. and Tsukamoto, H. (1969) 
Metabolism of drugs - LXII. Isolation and identification of morphine glucuronides in urine and bile of rabbits. Biochem. Pharmacol., 18, 279-286.

21) Shimomura, K., Kamata, O., Ueki, S., Îda, S., Oguri, K., Yoshimura, H. and Tsukamoto, H. (1971) Analgesic effect of morphine glucuronides. Tohoku J. Exp. Med., 105, 45-52.

22) Pasternak, G. W., Bodner, R. J., Clark, J. A. and Inturrisi, C. E. (1987) Morphine-6-glucuronide, a potent mu agonist. Life Sci., 41, 2845-2849.

23) Osborne, R., Joel, S., Trew, D. and Slevin, M. (1988) Analgesic activity of morphine-6-glucuronide. Lancet, 8589, 828.

24) Frances, B., Gout, R., Monsarrant, B., Cros, J. and Zajac, J.-M. (1992) Further evidence that morphine$6 \beta$-glucuronide is a more potent opioid agonist than morphine. J. Pharmacol. Exp. Ther., 262, 25-31.

25) Spiehler, V. R. (1998) Computor-assisted interpretation in forensic toxicology: morphine-involved death. J. Forensic Sci., 34, 1104-1115.

26) Coffman, B. L., Rios, G. R., King, C. D. and Tephly, T. R. (1997) Human UGT2B7 catalyzes morphine glucuronidation. Drug Metab. Dispos., 25, 1-4.

27) Bhasker, C. R., McKinnon, W., Stone, A., Lo, A. C. T., Kubota, T., Ishizaki, T. and Miners, J. O. (2000) Genetic polymorphism of UDP-glucuronosyltransferase 2B7 (UGT2B7) at amino acid 268: ethinic diversity of alleles and potential clinical significance. Pharmacogenetics, 10, 679-685.

28) Holthe, M., Rakvåg, T. N., Klepstad, P., Idle, J. R., Kaasa, S., Krokan, H. E. and Skorpen, F. (2003) Sequence variations in the UDP-glucuronosyltransferase 2B7 (UGT2B7) gene: identification of 10 novel single nucleotide polymorphisms (SNPs) and analysis of their relevance to morphine glucuronidation in cancer patients. Pharmacogenomics $J ., 3,17-26$ [Erratum in: Pharmacogenomics J., 3, 248 (2003)].

29) Hirota, T., Ieiri, I., Tanaka, H., Sana, H., Kawamoto, K., Aono, H., Yamasaki, A., Takeuchi, H., Masada, M., Shimizu, E., Higuchi, S. and Otsubo, K. (2003) Sequence valiability and candidate gene analysis in two cancer patients with complex clinical outcomes during morphine therapy. Drug Metab. Dispos., 31, 677-680.

30) Saeki, M., Saito, Y., Jinno, H., Tanaka-Kagawa, T., Ohno, A., Ozawa, S., Ueno, K., Kamakura, S., Kamatani, N., Komamura, K., Kitakaze, M. and Sawada, J. (2004) Single nucleotide polymorphisms and haplotype frequencies of UGT2B4 and UGT2B7 in a Japanese population. Drug Metab. Dispos., 32, 1048-1054.

31) Coffman, B. L., King, C. D., Rios, G. R. and Tephly, T. R. (1998) The glucuronidation of opioids, other xenobiotics and androgens by human UGT2B7Y(286) and UGT2B7H(286). Drug Metab. Dispos., 26, 73-77.

32) Duguay, Y., Báár, C., Skorpen, F. and Guillemette, C. (2004) A novel functional polymorphism in the uridine diphosphate-glucuronosyltransferase 2B7 promotor with significant impact on promotor activity. Clin. Pharmacol. Ther., 75, 223-233.

33) Wang, J. B., Imai, Y., Eppler, C. M., Gregor, P., Spivak, C. E. and Uhl, G. R. (1993) Mu opiate receptor: cDNA cloning and expression. Proc. Natl. Acad. Sci. U.S.A., 90, 10230-10234.

34) Uhl, G. R., Sora, I. and Wang, Z. (1999) The mu opiate receptor as a candidate gene for pain: polymorphisms, variations in expression, nociception, and opiate responses. Proc. Natl. Acad. Sci. U.S.A., 96, 7752-7755.

35) Lötsch, J., Skarke, C., Grösch, S., Darimont, J., Schmidt, H. and Geisslinger, G. (2002) The polymorphism A118G of the human mu-opioid receptor gene decreases the pupil constrictory effect of morphine-6-glucuronide but not that of morphine. Pharmacogenetics, 12, 3-9.

36) Skarke, C., Kirchhof, A., Geisslinger, G. and Lötsch, J. (2004) Comprehensive mu-opioid-receptor genotyping by pyrosequencing. Clin. Chem., 50, 640-644.

37) van Lingen, R. A., Simons, S. H., Anderson, B. J. and Tibboel, D. (2002) The effects of analgesia in the vulnerable infant during the perinatal period. Clin. Perinatol., 29, 511-34.

38) Gomes, I., Filipovska, J., Jordan, B. A. and Devi, L. A. (2002) Oligomerization of opioid receptors. Methods, 27, 358-365.

39) Gomes, I., Gupta, A., Filipovska, J., Szeto, H. H., Pintar, J. E. and Devi, L. A. (2004) A role for heterodimerization of $\mu$ and $\delta$ opiate receptors in enhancing morphine analgesia. Proc. Natl. Acad. Sci. U.S.A., 101, 5135-5139.

40) Taura, K., Yamada, H., Hagino, Y., Ishii, Y., Mori, M. and Oguri, K. (2000) Interaction between cytochrome $\mathrm{P} 450$ and other drug-metabolizing enzymes: evidence for an association of CYP1A1 with microsomal epoxide hydrolase and UDPglucuronosyltransferase. Biochem. Biophys. Res. Commun., 273, 1048-1052.

41) Taura, K., Naito, E., Ishii, Y., Mori, M., Oguri, K. and Yamada, H. (2004) Cytochrome P450 1A1 (CYP1A1) inhibitor $\alpha$-naphthoflavone interferes with UDP-glucuronosyltransferase (UGT) activity in intact but not in permeabilized hepatic microsomes from 3-methylcholanthrene-treated rats: possible involvement of UGT-P450 interactions. Biol. Pharm. Bull., 27, 56-60. 
42) Takeda, S., Ishii, Y., Iwanaga, M., Mackenzie P. I., Nagata, K., Yamazoe, Y., Oguri, K. and Yamada, H. (2005) Modulation of UDP-glucuronosytransferase function by cytochrome P450: evidence for the alteration of UGT2B7-catalyzed glucuronidation of morphine by CYP3A4. Mol. Pharmacol., in press.

43) Gianutsos, G., Cohen, S. D., Carlson, G., Heyman, R., Salva, P., Morrow, G. and Hite, G. J. (1986) Alteration of in vivo and in vitro effects of heroin by esterase inhibition. Toxicol. Appl. Pharmacol., 82, 14-18.

44) Pasternak, G. W. (2001) Incomplete cross tolerance and multiple mu opioid peptide receptors. Trends Pharmacol. Sci., 22, 67-70.

45) Kamendulis, L. M., Brzezinski, M. R., Pindel, E. V., Bosron, W. F. and Dean, R. A. (1996) Metabolism of cocaine and heroin is catalyzed by the same human liver carboxylesterases. J. Pharmacol. Exp. Ther., 279, 713-717.

46) Pindel, E. V., Kedishvili, N. Y., Abraham, T. L., Brzezinski, M. R., Zhang, J., Dean, R. A. and Bosron, W. F. (1997) Purification and cloning of a broad substrate specificity human liver carboxylesterase that catalyzes the hydrolysis of cocaine and heroin. J. Biol. Chem., 272, 14769-14775.

47) Dayer, P., Desmeules, J., Leemann, T. and Striberni, R. (1988) Bioactivation of the narcotic drug codeine in human liver is mediated by the polymorphic monooxygenase catalyzing debrisoquine 4-hydroxylation (cytochrome P-450 dbl/bufI). Biochem. Biophys. Res. Commun., 152, 411- 416.

48) Eichelbaum, M. and Evert, B. (1996) Influence of pharmacogenetics on drug disposition and response. Clin. Exp. Pharmacol. Physiol., 23, 983-985.

49) Stewart, D. J., Inaba, T., Tang, B. K. and Kalow, W. (1977) Hydrolysis of cocaine in human plasma by cholinesterase. Life Sci., 20, 1557-1563.

50) Carmona, G. N., Jufer, R. A., Goldberg, S. R., Gorelick, D. A., Greig, N. H., Yu, Q. S., Cone, E. J. and Schindler, C. W. (2000) Butyrylcholinesterase accelerates cocaine metabolism: in vitro and in vivo effects in nonhuman primates and humans. Drug Metab. Dispos., 28, 367-371.

51) Ambre, J., Ruo, T. I., Nelson, J. and Belknap, S. (1988) Urinary excretion of cocaine, benzoylecgonine, and ecgonine methyl ester in humans. J. Anal. Toxicol., 12, 301-306.

52) Bornheim, L. M., Lasker, J. M. and Raucy, J. L. (1992) Human hepatic microsomal metabolism of delta 1-tetrahydrocannabinol. Drug Metab. Dispos., 20, 241-246.

53) Watanabe, K., Narimatsu, S., Yamamoto, I. and Yoshimura, H. (1991) Oxygenation mechanism in conversion of aldehyde to carboxylic acid catalyzed by a cytochrome P-450 isozyme. J. Biol. Chem., 266, 2709-2711. 